\title{
Study Reference Publication Name
}

National Cancer Institute

\section{Source}

National Cancer Institute. Study Reference Publication Name. NCI Thesaurus. Code C94133.

A non-unique textual identifier specifying the human-readable name of the publication. 